\title{
What Makes Age Discrimination Special? A Philosophical Look at the ECJ Case Law
}

\author{
Axel Gosseries
}

Toutes les grandes personnes ont d'abord été des enfants.

(Mais peu d'entre elles s'en souviennent. $)^{1}$

Many people share the view that preventing those under 18 from voting is not as problematic as disenfranchising women or specific 'racial' groups. The same holds if we compare the prohibition on child labour or practices of age-based compulsory retirement, with the exclusion from the job market of women or of certain 'racial' groups.

This paper aims at formulating and critically examining reasons that may explain and justify why age is - and/or should be - treated differently by anti-discrimination law, compared to other suspect grounds such as 'race' or gender. ${ }^{2}$ It is motivated by an observation and an assumption. First, anti-discrimination law, both in the US and in the EU, seems to treat age in a more lenient way than these other suspect grounds. In the US, age is not covered by title VII of the 1964 Civil Rights Act and the 1967 Age Discrimination in Employment Act deals with differential treatment above the age of 40 only. Similarly, in the EU, Directive 2000/78/EC includes specific provisions for age - notably article 6 - that leave more room to Member States than it does for other suspect grounds. Also, there is no equivalent for age of the 'goods and services' directives applicable to gender (Directive 2004/113/EC) and 'race' (Directive 2000/43/EC). Second, the fact that legal systems still rely heavily on age limits and that anti-discrimination law allows for it to some extent seems to be backed by the moral intuition that age differs from other suspect grounds. This triggers our interest in finding out whether age is really different, in what sense it is so, and whether these differences justify a more lenient treatment than for gender or 'race.'

* The ideas developed here were presented on various occasions in 2012 and 2013, including in Paris, Tbilisi, Copenhagen, Brussels, Louvain-la-Neuve, Melbourne, Campinho, York and Fribourg. I wish to thank these audiences as well as B. Allaez Corra, H. Brighouse, G. Calvès, A.-F. Colla, D. Desmette, E. Dubout, N. Eyal, A. Hosein, D. Martin, T. Meijers, M. Mercat-Bruns, H. Pourtois, D. Sabbagh, J. Suck, Chr. Tobler, P.-E. Vandamme and Ph. Van Parijs. While any remaining errors are my own, the quality of this paper doubtlessly gained a lot from interactions with all of them. Many thanks as well to my ENASS students, to two referees from NJLP as well as to R. Pierik, one of the editors of NJLP.

1 Antoine de St Exupéry, Le Petit Prince (New York: Harcourt, Brace \& World, 1943), dedication.

2 I won't discuss why anti-discrimination law does not also cover wealth/income-based differential treatment (e.g., in access to education or housing) or intellectual-ability-based differential treatment (e.g., in employment). 
Consider now the basic observation that our age changes along our lives, in a way in which our 'race' or gender don't. ${ }^{3}$ However, the changing nature of age is a fact that does not tell us as such whether and why this should lead to a more lenient moral and legal treatment of age-based differential treatment. Moreover, we should not forget that our age remains a feature that none of us has chosen, in the same way as our 'race' or - in nearly all cases - our gender. Experiencing a change in our age is thus quite different from deciding to change shoes. The fact that a feature is beyond our control is one aspect that can account for the need to include it within the list of suspect grounds. Hence, underlining the fact that our age changes does not render it less true that we don't chose the starting point, the direction and the speed of the (chronological) ageing process that the passage of time imposes on us.

I don't intend to question the fact that we all age at all - which does not entail that I endorse the view that all of us will end up having the chance of being part of each age-group. I will also endorse the view that this fact is central in explaining why age-based differential treatment may be less problematic than differential treatment on other grounds. However, we need an account of why this fact makes a difference to the moral acceptability of age-based differential treatment in a certain set of circumstances. I will successively consider several accounts. I will aim at applying to each of these accounts the following test: (1) Does the fact that our age changes actually play a central role in the account? (2) Is the account independent from the other accounts? (3) How broad is the scope of the account, i.e., does the specific account apply to all cases of age-based differential treatments or to a limited set of age-based practices? (4) Is the account of the distinctiveness of age actually able to justify a more lenient regime for age-based differential treatment?

Note as well that I will not aim here at an exhaustive list of possible accounts. I will focus on six of them. On top of these six, some people believe that age is also special because, contrary to 'race' for example, it is not to be understood against the background of historical injustice. For instance, in its June 25, 1976 Massachusetts Board of Retirement v. Murgia decision, the US Supreme Court formulated the view that 'while the treatment of the aged in this Nation has not been wholly free of discrimination, such persons, unlike, say, those who have been discriminated against on the basis of race or national origin, have not experienced a "history of purposeful unequal treatment" or been subjected to unique disabilities on the basis of stereotyped characteristics not truly indicative of their abilities' (my italics). I am not sure that this claim is true. We may look back and actually conclude that there has been massive injustice towards certain age groups in the past. This

3 Note the interesting case of sequential (or successive) hermaphroditism in certain animal species (e.g., certain fishes, oysters) or plant species (referred to in the latter case as dichogamy). See e.g., Thos. H. Montgomery, Jr., 'On Successive, Protandric and Proterogynic Hermaphroditism in Animals,' The American Naturalist 29 (1895): 528-36; Michael T. Ghiselin, 'The Evolution of Hermaphroditism among Animals,' The Quarterly Review of Biology 44 (1969): 189-208; Erem Kazancioğlu \& Suzanne Alonzo, 'Costs of Changing Sex do not Explain why Sequential Hermaphroditism is Rare,’ The American Naturalist 173 (2009): 327-36. 
will depend on the view we adopt on what justice between age groups requires. I am also not sure that even if it were true it should be central. This is so for at least two reasons. As it is the case for gender too, current generations don't inherit advantages and disadvantages from specific age groups as they may from specific ethnic groups. Second, even in the case of racial discrimination, historical injustice may not provide the most robust account of why anti-discrimination policy is strongly needed. A plain intra-generational distributive account may offer better grounds.

In the course of this paper, I will refer to some of the European Court of Justice (ECJ) cases insofar as they echo the accounts discussed. There is now, since Mangold (2005, C-144/04), a body of nearly thirty ECJ decisions dealing with agebased differential treatment in relation with Directive 2000/78/EC. ${ }^{4}$ References will build here on earlier, more specific and - in some cases - more strictly "black letter' legal work published elsewhere, ${ }^{5}$ the point of the present paper being to provide an account of a more philosophical nature. Our goal will be to formulate possible accounts of why age-based differential treatment may be less objectionable than, e.g., gender-based or 'race'-based differential treatment. We will aim at understanding how these accounts are inter-related, how philosophically robust each of them is and whether we should attach significant practical implications to each of them, especially from the perspective of anti-discrimination law.

\section{Age as a Reliable Proxy}

In everyday life, age is used in a very significant set of cases as a proxy, as an approximate substitute, as an indicator of something else, of a target variable. ${ }^{6}$ This is so, e.g., in insurance, on the labour market, or in, e.g., family, criminal, tort, electoral laws. Age is typically associated with certain levels of intellectual, affective or physical abilities. We assume that people below a certain age don't yet

4 For a list of the first 26 cases: Anne-France Colla and Axel Gosseries, 'Discrimination par l'âge et droit transitoire. Réflexion à partir de Commission c. Hongrie (C-286/12), Journal des tribunaux du travail 43 (2013): 69-81, at note 6.

5 See Axel Gosseries, 'La singularité de l'âge. Réflexions sur la jurisprudence communautaire,' Mouvements 59 (2009): 42-54; Colla \& Gosseries, 'Discrimination par l'âge et droit transitoire' (focusing on issues of age discrimination and rule change, looking at the ECJ case law as well as the Belgian Constitutional Court one); Axel Gosseries, 'La discrimination par l'âge en assurance à la lumière du droit européen du travail,' Revue générale des assurances et des responsabilités 86 (2013): 1489 (looking at the implications of the ECJ labour-focused case law for insurance law); Axel Gosseries, 'Euthanasie des mineurs: pourquoi un critère d'âge?,' La Revue Nouvelle 68 (2013): 74-84 (looking at the Belgian debate on the extension to minors of the law decriminalizing euthanasia).

6 See as well below, section 3 and Gosseries, 'Euthanasie des mineurs,' 75 (example involving the use of an age criterion for organ allocation under a fair innings approach where it does not seem to be a proxy). Note that age can fulfil other functions than a proxy one. On its signalling function, consider the fact that some of the prohibitions imposed on younger people (e.g., those related to sexual majority) attract their attention to the risks involved in doing certain things before a certain age. Thanks to M. Matravers for this. 
have certain abilities, or that people above that age tend to lose some of them. While the use of proxies may be defensible, all things considered, it is of course not totally unproblematic. ${ }^{7}$ In cases where it is deemed acceptable, it is generally so for efficiency reasons, the target variable being less easily observable than a person's age in many contexts. Efficiency, while clearly relevant from the perspective of theories of justice, including those with a strong distributive component, may, however, not be the only reason to rely on a proxy. While labelling the underlying rationale is not easy, it appears that preferring age limits to, e.g., literacy tests in electoral law, or to individualized assessments of a person's affective maturity in matrimonial law, doesn't derive only from efficiency-driven concerns. ${ }^{8}$ Note however that while one may think that relying on, e.g., age-based compulsory retirement could be less stigmatizing than individualized productivity assessment, it may be that not stigmatizing less productive individuals comes at the cost of stigmatizing a whole age-group instead. Moreover, if an age criterion is supposed to be justified through its proxy function, the criterion becomes redundant - and unjustifiable - whenever the law mandates an individualized assessment of the very same target feature. The debate on legalizing euthanasia for minors is a case in point. The need for an age criterion in such a case is questionable as the ability of the young patient to fully understand the consequences of its decision needs to be assessed in an in-depth manner anyway in euthanasia cases. $^{9}$

It is one thing to point at the use of age as a proxy. It is another to account for the reasons and the degree to which age would be an especially reliable proxy. Actually, when anti-discrimination activists combat stereotypes, they tend for one part to question the reliability of the proxy at stake. Let me discuss here two accounts of the special reliability of age. Consider first Advocate General Jacobs in his opinion under Lindörfer (2007, C-227/04 P):

'Sex is essentially a binary criterion, whereas age is a point on a scale. Sex discrimination based on actuarial tables is thus an extremely crude form of discrimination, involving very sweeping generalisations, whereas age discrimination may be graduated and may rely on more subtle generalisations' (point 84). vard University Press, 2006), esp. Chapter 4 on age.

8 Ibid., 122.

9 For further developments: Gosseries, 'La discrimination par l'âge en assurance à la lumière du droit européen du travail' and 'Euthanasie des mineurs.' Besides removing an age limit, one may replace it with a specific age-triggered test. On age-triggered tests vs. age-triggered exclusion: Schauer, Profiles, Probabilities and Stereotypes, 128. On the risk associated with having different tests and procedures for different age groups in the case of euthanasia: Gosseries, 'Euthanasie des mineurs,' 80. 
I don't think that the insistence on non-binarity is key here. ${ }^{10}$ What is of interest however in A.G. Jacobs's opinion is that the high divisibility of our lifespan into numerous age groups allows for less rough, more refined approximations than what is possible for other criteria. For those worried about approximation from the perspective of fairness, this is a strength of age as a proxy.

Divisibility does not only allow for more precision and less rough approximations. It also allows us to reduce the risk of systematic discrimination through diversification, which is another advantage. We rely on a variety of age limits (e.g., 10, 12, $14,16,18,21)$. This has the advantage of less systematically excluding a single age category through cumulating the effects of a single age criterion in various domains of life (e.g., education, employment, housing, health). While the multiplicity of age criteria could be seen as a sign of inconsistency - and I suspect it is inconsistent whenever different age limits are used as proxies of basically the same type and level of ability -, this multiplicity has at least the merit of reducing the concentration at specific ages of disadvantages associated with differential treatments in various areas of life. Let me add that another feature contributes to this: while in a sexist or 'racist' society, differential treatment tends to more systematically disadvantage one of the groups at stake (typically women or 'nonwhites'), age limits tend to operate less systematically against those above or below the age at stake. Its 'direction' depends more on the type of policy.

Be that as it may, I would argue that the strength - in factual terms - of age as a proxy rests more with its connection with the passage of time than with the precision and the diversification that its high divisibility allows for. ${ }^{11}$ There is no question that chronological age and the passage of time are perfectly correlated. The crucial issue is whether the passage of time and our level of intellectual, physical, affective abilities - i.e., the target variables - are significantly correlated as well. While time is not the only relevant variable here, it is clear that learning takes

10 Recall here the 14 December 1995 opinion of Advocate General Tesauro under the first ECJ transgender case ( $P$ v. S and Cornwall County Council, C-13/94, April 30, 1996) referring to the 'Adam and Eve' approach, more than ten years before the Lindörfer case:

'I shall start by calling to mind the proposition, which has ever stronger support in medical and scientific circles, that it is necessary to go beyond the traditional classification and recognize that, in addition to the man/woman dichotomy, there is a range of characteristics, behaviour and roles shared by men and women, so that sex itself ought rather to be thought of as a continuum. From that point of view, it is clear that it would not be right to continue to treat as unlawful solely acts of discrimination on grounds of sex which are referable to men and women in the traditional sense of those terms, while refusing to protect those who are also treated unfavourably precisely because of their sex and/or sexual identity.

The argument just put forward, attractive as it is, requires a redefinition of sex which merits deeper consideration in more appropriate circles; consequently, this is not the path that I propose that the Court should follow. I fully realize that from time immemorial a person's sex has merely been ascertained, without need of the law to define it. The law dislikes ambiguities and it is certainly simpler to think in terms of Adam and Eve. (...)' (\$17, my italics).

11 While distinct, the two issues are of course not totally independent. Precision can only be a virtue if we gain precision in predicting something, which requires a strong correlation between age and the passage of time and between the passage of time on the target variables. 
time, that gaining experience takes time and that as time passes some processes may lead both to the development of our bodies and capacities and to their degradation (e.g., fertility, physical strength, ability to speak). What is central is the weight of the time factor compared to other factors such as one's genetic material, one's family environment, the level of development of one's country, the quality of one's physical environment, etc. We can say that the reliability of age as a proxy is certainly strong at very early and very advanced ages (e.g., the working ability of those below 14, the emotional maturity of those below 16, the driving ability of those below 25 , the physical strength of those above 50 , the health condition of those above 85 ). In contrast, when comparing people within the middle range (e.g., a 35 and a 45 years old), many other factors often play a more significant role and intra-age-group variability then often becomes stronger than interage-groups variability. ${ }^{12}$ As a significant number of age limits are low or high ones, it seems that such age limits can be seen as involving relatively reliable proxies of some target characteristics.

At this stage, we can draw two conclusions. First, in objective terms, age is not at all irrelevant when it comes to assessing certain abilities. Second, our assessment of age limits at the extremes of life should differ from our assessment of midlife age limits. A further question - that we won't discuss here - is whether lower and upper age limits are equally reliable for each of the different types of abilities (physical, intellectual, emotional).

By way of illustration, let us now look at the extent to which the ECJ accepts the use of age as a proxy. ${ }^{13}$ In at least six of its decisions on age-related issues, the court does not object to the very idea of using age as a proxy. In Wolf (2010, C-229/08, operational firemen) and Petersen (2010, C-314/08, dentists), the Court does not question the assumption of a reduction of people's abilities beyond certain ages (respectively 45-50 and 68). In Prigge (2011, C-447/09, pilots), it does not reject it either, although it does question the specific age chosen (60 instead of 65). While the court clearly accepts the use of age as a proxy for physical abilities in Wolf and Prigge - things being less explicit in Petersen -, it rejects in Hennigs \& Mai (2011, C-297/10 and C-298/10) the conformity of a measure involving differential pay grounded on the alleged correlation between a person's age and her financial needs. Two further cases are also of interest. In Georgiev (2010, C-250/09, academics), the Court accepted a certain correlation between age and competence, not in an individual but in a collective sense. ${ }^{14}$ The coexistence of people of different ages is supposed to lead to a fruitful confrontation of different worldviews, which may increase the quality of academic output

12 Thanks to D. Desmette on this.

13 For a more detailed analysis, including a look at Directive 2000/78/EC, at some French and Belgian cases: Gosseries, 'La discrimination par l'âge en assurance à la lumière du droit européen du travail,' $\S 11-21$.

14 See, however, the discussion on the age-experience link in Hennigs \& Mai (2011, C-297/10 \& C-298/10). See as well Thomas Hess, 'Memory and Aging in Context,' Psychological Bulletin 131 (2005): 383-406; Thomas Ng \& David Feldman, 'The Relationship of Age to Ten Dimensions of Job Performance,' Journal of Applied Psychology 93 (2008): 392-423. 
in this case. In none of the cases, however, is the Court explicit about a connection between age and individual intellectual performance. As to Parliament $v$. Council (2006, C-540/03), a case dealing with the right to family reunification of minors, the ECJ accepts the use by Directive 2003/86/EC of the age of 12 as a proxy of the capacity of a child to integrate in a new country (\$ 65-69).

The point here is not to discuss each and every of these cases on its substance. It is also beyond the scope of this paper to discuss whether the treatment of age as a proxy by the ECJ differs from its treatment of, e.g., gender as a proxy. What matters here is to show that the Court is explicit about the use of age as a proxy in these cases. It does not question the legality of using it with such a purpose, ${ }^{15}$ even though it may question either the use of a specific age given the target variable at hand (as in Prigge) or the relevance of age in general for a given target variable (as in Hennigs \& Mai).

What we have is a clear position by the ECJ on the acceptability of age as a proxy in certain cases. And I offered above an account of why age could be seen as a reliable proxy. Now, this leaves us with an important difficulty. In a very racist society, 'race' is probably a reliable proxy - in the objective sense of the word - for various types of abilities. By this, I mean that if people from a given 'race' or ethnic group are systematically denied access to certain schools or jobs, the fact of belonging to such a group will be a reliable proxy to predict the level of skills that those who are not being denied access tend to gain in such schools or jobs. Similarly, in a very sexist society, gender is probably quite a reliable proxy for a certain set of abilities that people learn at places from which women remain excluded. ${ }^{16}$ What this shows is that it is not enough to point at the reliability of a proxy to make its use morally acceptable. Even in societies in which 'race' and gender are very reliable proxies, it does not necessarily follow that we should find it morally acceptable to use such criteria in employment, in the exchange of goods or in the provision of services. What this indicates is that the 'reliable proxy' account is insufficient to ground the moral and legal acceptability of age criteria. In order for age to be a morally acceptable criterion, we need to show that what makes it reliable is not itself morally problematic, as it is in the case of racist or sexist ways of organizing society that render 'race' or gender reliable proxies.

This suggests two things. First, the evolution of our abilities does not purely result from the passage of time as a natural fact. It results from the conjunction of the passage of time and the type of age-based structure that our societies associate with it. Many people believe, for instance, that it is better in general to concentrate education at the beginning of people's lives and then to put people to

15 See the explicit statement of the US Supreme Court in its March 30, 2005 Smith v. City of Jackson decision: '(...) age, unlike race and other classifications protected by Title VII [of the Civil Rights Act of 1964], not uncommonly has relevance to an individual's capacity to engage in certain types of employment. To be sure, Congress recognized that this is not always the case, and that society may perceive those differences to be larger or more consequential than they are in fact.'

16 For a classic: Edmund S. Phelps, 'The Statistical Theory of Racism and Sexism,' American Economic Review 62 (1972): 659-61. 
work rather than the reverse. And the reliability of specific early ages as proxies is probably due in part to the fact that compulsory education tends to standardize the development of people's competences at the beginning of their life.

This points to a second idea. If we accept the view that the reliability of age as a proxy derives at least in part from the age-based nature of our social organization, we need an independent argument able to explain us why some degree of agebased social organization - 'ageist' in the non-psychological sense of the word -, is not necessarily as problematic as a racist or as a sexist social organization. In a sense, insisting on the reliability of age as a proxy confronts us with the following challenge. We may want to claim that age criteria are acceptable because age is a good proxy. However, if age is a good proxy in part because society is organized around age criteria, we fall into circularity unless we come up with an extra argument to justify such 'prior' age criteria, such age-based social structuration in the first place.

Let us then take stock and apply our fourfold test. The fact that our age changes is definitely central to the 'reliable proxy' account. The scope of this account is very broad. If conclusive, it could justify some degree of extra leniency towards certain forms of age-based differential treatment. However, what we have shown is that its validity is necessarily dependent on another argument able to tell us how to connect the strong reliability of certain age criteria as a proxy with their moral acceptability. The next sections will be devoted to proposing such extra account(s).

\section{Age Limits and Complete-Life Neutrality}

One serious candidate for a complementary account to the 'reliable proxy' one is what I will refer to as the 'complete-life neutrality' account of the specialness of age. It consists in connecting, on the one hand, a claim as to which metrics fairness concern should adopt and, on the other hand, what adopting such a metrics tells us about age-based forms of differential treatment.

Let me begin with sketching the first of these two components, i.e., the completelife view. ${ }^{17}$ It says that for most distributive theories of justice (plain egalitarianism, leximin egalitarianism, prioritarianism), what matters primarily - and for some variants, exclusively - is how each of us fares over her complete life, as opposed to at any given moment in time or between corresponding stages of our lives. For instance, if you defend equality over complete lives (or 'whole lives') egalitarianism, you will claim that the existence of inequalities at a given moment in time between people of different ages (e.g., those above and below 18 at the 2014 elections) or at different moments in history between people of the same age (e.g., those above 65 in 2005 and in 2020 in relation to their retirement

17 For further developments: Dennis McKerlie, Justice between the Young and the Old (Oxford/New York: Oxford University Press, 2013), Chapter 2; Samuel Kerstein \& Greg Bognar, 'Complete Lives in the Balance,' The American Journal of Bioethics 10 (2010): 37-45. 
benefits), ${ }^{18}$ does not matter as long as they don't translate into inequalities over complete lives. Note that what the complete-life view calls for, whenever we face situations involving several generations, is cohortal analysis, which requires comparisons over long periods as well as the anticipation of the future effects of alternative scenarios.

We lack space here to discuss what underlies the complete-life view as well what its different versions amount to. ${ }^{19}$ Let me insist, however, on the fact that the account of the specialness of age that rests on it will depend on a proper understanding and defence of the complete-life view. Note for instance that views of justice that give some space to responsibility are more likely to defend a complete-life view. Let me also illustrate two ways in which the complete-life view could be understood and challenged, through a confrontation with one specific theory of justice, i.e., sufficientarianism. The latter theory tells us that rather than requiring that inequalities be reduced (classical egalitarianism) or that the situation of the least well-off be improved as much as possible in absolute terms, be it at the cost of increasing inequalities (maximin or leximin egalitarianism), justice requires that each of us has enough. ${ }^{20}$

Sufficientarianism can then interact with the complete-life view in the two following ways. Some people defending what is called the 'fair-innings' view consider that we should define a lifespan that is sufficient to what an accomplished life requires. ${ }^{21}$ If we set it at the age of 70 for instance, it means that in terms of, e.g., health care allocation, resources should be devoted to making sure that as many people as possible reach the age of 70 rather than to prolonging people's lives beyond that age. This account does not conflict with the complete-life view. It endorses it while offering a sufficientarian view of it that puts special emphasis on lifespan.

Contrast this with another sufficientarian claim that says that the complete-life view should be amended because each of us should have enough (food, shelter, etc.) at every moment in time, all along our life, as opposed to over our complete lives only. This continuist approach to what justice requires calls for not limiting ourselves to the complete-life view in certain areas that touch upon very basic needs. ${ }^{22}$ Whenever the lack of coverage of some basic needs at a given point in time does not necessarily lead to increasing complete-life inequalities - e.g., because it is more than compensated at a later point in life -, the demands of continuist sufficientarianism and of (pure) complete-life egalitarianism will diverge. Complementing the complete-life view in this way may lead for instance to chal-

See on this the discussion on the simultaneous segments and the corresponding segments views in McKerlie, Justice between the Young and the Old.

19 See e.g., ibid.; Norman Daniels, Am I My Parents Keeper? An Essay on Justice Between the Young and the Old (New York: Oxford University Press, 1988).

20 See, e.g., Paula Casal, 'Why Sufficiency Is Not Enough,' Ethics 117 (2007): 296-326.

21 See Harris discussed in Kerstein \& Bognar, 'Complete Lives in the Balance.'

22 See Axel Gosseries, 'Qu'est-ce que le suffisantisme?,' Philosophiques 38 (2011): 465-92, at 482-6; Juliana Bidadanure, 'In Defense of the PLA,' American Journal of Bioethics 13 (2013): 25-7. 
lenging age criteria more strongly in, e.g., housing policy or health care than in, e.g., employment or higher education, i.e., whenever people's ability to cover their basic needs is more likely to be jeopardized.

Hence, sufficientarian intuitions can both provide a specific reading of what the complete-life view requires (fair innings) and reasons to complement it with more stringent requirements in certain domains of our lives (continuist intuition). We will emphasize below another reason why complete-life equality may not be enough, i.e., whenever age limits reduce people's freedom in unnecessary and/or inefficient ways. However, let us assume for a moment that the complete-life view is the right view from a philosophical angle, ${ }^{23}$ be it with some continuist amendments. We now need to bridge this view with what it entails for the moral acceptability of age criteria. What is clear is that the complete-life view allows us to go beyond the claim according to which being disadvantaged by age criteria is less serious because it lasts only during part of our life (the 'merely temporary harmfulness' account). I don't think that being excluded from a given entitlement during twenty years or from the age of 60 till the end of our life is significantly less serious than, e.g., being excluded from access to only part of the social opportunities during all our life as a woman or as a member of a given ethnic group. The fact that age criteria sometimes only have a temporary impact is not sufficient.

The 'complete-life neutrality' account goes beyond a 'merely temporary harmfulness' account of the specialness of age-based differential treatment. While downplaying the importance of the age-based practice, the merely temporary harmfulness view remains compatible with significant inequalities. In contrast, the argument from complete-life neutrality claims that age-based differential treatment at a given moment in time is less problematic than gender-based or 'race'based ones because it does not necessarily lead to any differential treatment over complete lives. If members of overlapping cohorts are all excluded from the right to vote before the age of 18 and if a set of other conditions are met, the age criterion will not necessarily lead to any differential treatment over people's complete lives in terms of access to electoral power. This is admittedly a very specific feature of age - one that it shares under specific conditions with 'seniority. ${ }^{24}$

However, we should not overestimate the practical significance of this feature. While it is true that age-based differential treatment will not necessarily lead to differential treatment over complete lives, it often does in practice. And it does so through a conjunction of changes in the age criteria and/or of the environment in which such criteria operate. Of course, if changes obtain with respect to the age criteria, it will tend to have an impact in terms of complete-live inequalities between the successive generations. ${ }^{25}$ This is so whenever age limits are intro-

23 Note that while the simultaneous segments view is not, the corresponding segments view is compatible too with age-based differential treatment.

24 On seniority: Axel Gosseries, 'Are Seniority Privileges Unfair?,' Economics \& Philosophy 20 (2004): 279-305.

25 See Axel Gosseries \& Mathias Hungerbühler, 'Rule Change and Intergenerational Justice,' in Handbook of Intergenerational Justice, ed. J. Tremmel (Cheltenham: Elgar, 2006): 106-28. 
duced (e.g., new age-triggered tests for elderly drivers), removed (e.g., euthanasia for minors), lowered (e.g., voting age in some countries) or raised (e.g., minimum age for pension benefits). However, even if age criteria don't change, the environment might, which irremediably leads to a differential impact on members of successive generations too. Fluctuations on the labour market (e.g., in terms of unemployment rate) lead to very different impacts of a given age-based practice. Similarly, a given retirement age may lead to very different budgetary impacts if birth rates go down and longevity rises. Even within a given cohort, an age criterion can have a very different impact between, e.g., people with very different life expectancies.

This shows that age limits - through their own change or through their interactions with changing environments - often will lead to differential treatment over complete lives. Moreover, an additional problem arises with this negative defence of age-based differential treatment. Imagine a sexist society largely organized in a rotating manner along gender divides. ${ }^{26}$ The order of rotation could be decided by the toss of a coin, which would avoid giving priority in a more expressive and richer sense to a given gender. Moreover, rotation would not have to be simultaneous for all types of goods. As it would not cover each and every type of activity, such a rotation would also be compatible with the absence of serious segregation, as people from both 'sides' of the gender divide would still meet on a daily basis during their free time. In such a sexist society, on year 1, women would, e.g., have all the political power while men would, e.g., benefit from exclusive access to paid labour. On year 2, roles would be reversed, etc. This would amount to a sequential form of a gendered division of labour. I don't think that this system would need to be interpreted as demeaning or insulting towards any of the gender groups. As a division of labour, it could possibly lead to efficiency gains. However, does the gendered aspect add any extra benefits to it?

So, here is the argument. Let us assume that this scheme would not lead to any differential treatment over complete lives, which would make it acceptable from a 'complete-life neutrality' perspective. Such a 'gendered rotation' society would still leave us with the impression that there is something wrong with it, which suggests that the defensive 'compete-life neutrality' strategy is insufficient. It is not entirely clear from the example whether the wrongness of gendered rotation would come from the rotation as such (e.g., from its too high frequency or from the fact that such rotation may be good for power but not for paid labour) or from its gendered nature. I suspect that it comes at least in part from the latter. The claim would be that whenever taking turns can be shown to have positive effects (which can be the case, e.g., in politics), it still remains to be shown that doing so along gendered or 'racial' lines adds extra benefits. I suspect it doesn't in most cases. So, here is a case of a practice that is neutral from a complete-live per-

26 See McKerlie, Justice between the Young and the Old, 58-60; David Estlund, 'Beyond Fairness and Deliberation: The Epistemic Dimension of Democratic Authority,' in Deliberative Democracy. Essays on Reason and Politics, ed., James Bohman \& William Rehg (Cambridge: MIT Press, 1997), $191 \mathrm{ff}$ ('Queen for a Day' case). 
spective, that is not demeaning to a specific group, but that still restricts people's freedom in unnecessary ways. If the defensive complete-life account is insufficient in such gender- or 'race'-focused cases, I suspect it is also insufficient to justify age-based differential treatment. If we want to show that age is special and that it is so to the point of being morally more acceptable, we need further steps again.

\section{The Sequencing and Isogenic Functions of Age Criteria}

There are at least two ways in which one can defend age criteria in non-defensive terms that are independent from the 'reliable proxy' account. The first one insists on the efficiency gains resulting from developing certain skills, completing certain tasks in a certain chronological order along our lives. The second one stresses upon the fact that certain age criteria actually promote equality over complete lives. While the 'complete-live neutrality' account amounts to a defensive egalitarian strategy, these two accounts of the specialness of age can respectively be labelled 'sequence efficiency' and 'affirmative egalitarian', for reasons that I am now going to explain.

Let me begin with the 'sequence efficiency' defence. We find it efficient to organize our social existence along time criteria. For instance, considering the daynight succession, most of us will agree that it is more efficient if most of us sleep at night and work during the day, than the reverse. This is so at least to the extent that roughly adjusting to the availability of natural light is beneficial overall. We then find it acceptable if societies set up rules or incentives for people to follow this day-night pattern. Considering, e.g., compulsory education, kids are expected to show up at school during the day, not during the night. Along the same lines, we find it efficient that the longest holidays of the year take place during the hottest season where it is harder to work and nicer to enjoy leisure time. This means that taking into account the variations in outside temperature is desirable. Hence, in the case of compulsory school attendance again, kids are typically not expected to come to school during the summer months in the northern hemisphere.

The time-structure of our social organization thus takes, e.g., natural light (nightday) and natural temperature (winter-summer) into account. It also gives importance to the chronological order of our activities, their sequence, whether we do $\mathrm{x}$ before $y$ or the reverse. In many situations, there are very significant gains associated with following a specific sequence. Think about the benefits of early action in climate policy, about the steps of an emergency procedure in a hospital or about the importance of taking cumulative learning seriously in school curricula. Expressions such as 'Think first, act second' also capture ways of translating the 
importance of following a given sequence of actions. ${ }^{27}$ This 'chronological order' idea is crucial to understand the benefits of using age criteria as the latter can be seen as ways of promoting the former. Consider age-based compulsory education again. One of its justifications is that we find it more efficient for people to learn certain things first, before engaging in professional activities. A regime of compulsory education that would expect people to have attended school during their life while letting people free to choose at which age they want to start primary school would not be as efficient. This supports the claim that for a series of age criteria, what is at stake is not merely to adapt - reactively - to natural, age-related abilities. Instead, it is about actively forcing or incentivizing people to follow a given chronological sequence. Age limits are there to tell people how they should organize the timing of their lives. And this may be defensible if the efficiency gains associated with this restriction of people's freedom are significant enough.

Let me then add a few comments before examining the other affirmative defence. First, there is a difference between the 'rotational', 'taking turns' example discussed in the previous section and the 'sequence efficiency' idea. Taking turns insists on dividing labour or power. We could imagine a society that would be divided up into ten age groups (numbered from 1 to 10). It would grant exclusive political power to even age groups and exclusive job market access to odd age groups during a first period. During the next period, it would simply reverse the order, and so on and so forth. This could be neutral up to a certain extent from a complete-life perspective. However, it would lead to benefits associated with an alternating sequence, but not with those of a cumulative sequence. Age criteria can achieve the latter because we talk about different stages of the same person, about learning processes, which is not the case with gender or 'race.'

Second, should we say that the 'sequence efficiency' idea supports the claim that age criteria can be used (actively) to order, to organize people's sequence of actions, on top of being used in other respects (reactively) as proxies to assess the actual abilities of individuals? I would tend to say so. Again, considering compulsory age-based education, we probably use age for both reasons. We don't want children to start learning certain things after a certain age because we think that learning them early is better (e.g., speaking a foreign language). But we also force them to start learning them before a certain age onwards because we think it is efficient that they engage in learning them before learning or doing something else (e.g., learning the basics of a language before reading its most brilliant novelists). Note here that seniority is a good substitute for age when it comes to the latter's sequencing function, e.g., in a firm. Note as well that we should not confuse the efficiency gains associated with relying on a proxy with the efficiency gains associated with people following a certain sequence.

27 To come back to the example of sequential hermaphroditism, biologists are also interested in finding out for such living beings under which conditions protandry (i.e., male first, female second) is a better strategy than protogyny (i.e., female first, male second). 
Third, does the complete-live view play a central role insofar as this sequencing function of age is concerned? Its role is indirect and can be understood in two ways. On the one hand, the sequencing function of age is made less problematic by the relative complete-life neutrality of age criteria. On the other hand, efficiency gains can of course be used to improve the situation of those who are the least well-off over complete lives, provided that we organize society in a certain way.

Let us now turn to the other affirmative defence. It focuses on equality rather than efficiency. It claims that age criteria can be isogenic, i.e., can contribute to reduce inequalities over complete lives. Contrary to what happens with the 'sequence efficiency' account, the complete-life view plays a central role here. It allows us to see why age criteria that mechanically increase spot inequalities in an overlapping cohorts world may still be desirable from an egalitarian perspective. Also, to link it with the 'complete-life neutrality' account, it is possible to defend both the view that certain types of age criteria will often lead in practice to differential treatment over complete lives, and that other age criteria can actually reduce complete-life inequalities and/or improve the complete-life opportunities of the least well-off.

The isogenic effects resulting from age criteria can typically be observed in the case of some upper age limits that tend to shift resources towards the young, be it, e.g., in health care or in employment. ${ }^{28}$ Compulsory retirement can be understood in this light, even though one may discuss whether it should apply to all types of jobs and whether it should be based on age rather than other proxies better able to capture a person's cumulated access to job opportunities. ${ }^{29}$ Within each cohort, compulsory retirement tends to concentrate jobs in the hands of the middle-aged which can be seen as isogenic if we consider those who will be unlucky not to be in good shape after the age limit or even not to reach it alive - at least if their condition is independent from the fact of concentrating paid activity on a shorter period of people's life. Across different cohorts, compulsory retirement frees jobs for people from the following birth cohort. One may of course claim that they will themselves have to do the same for the next cohort. It still remains true that even if the measure is imposed on all successive cohorts, ceteris paribus, - and leaving efficiency aside - it tends to reduce inequalities in access to jobs across cohorts, as any job-sharing scheme does. To take another example, compulsory school attendance up to a certain age might also be seen from the same Can!' (Paris: PSE Working Paper, 2010).

29 For a discussion on this: Gosseries, 'La discrimination par l'âge en assurance à la lumière du droit européen du travail,' $§ 27$. 
inter-cohortal perspective. ${ }^{30}$ Interestingly enough, age-based compulsory education thus seems to be supported by each of the three complete-life related accounts, i.e., the 'complete-life neutrality', the 'sequence efficiency' and the 'affirmative egalitarian' one. Note finally that adjusting age limits over time (e.g., modifying the age at which people are entitled to claim pension benefits) may be another way in which age limits can contribute to the reduction of inequalities.

This leaves us with at least two questions. First, do we find traces in the ECJ case law of the complete-life view as being central to the understanding of the distinctiveness of age, and of any of the three accounts associated with it so far, i.e., the 'complete-life neutrality', the 'sequence efficiency' and the 'affirmative egalitarian' ones? There does not seem to be any explicit reference to that view. In the age cases, the Court does not question at the first step of her reasoning the very existence of a difference of treatment. Does it follow that she rejects the complete-life view? I don't think so, as we have shown why it is implausible to claim that age limits will necessarily generate no differences of treatment over complete lives. Indirectly, one could try and find support for the view that the Court endorses the complete-life view through identifying the types of age limits that the Court turned down and those that it still considers acceptable (such as age-based compulsory retirement). Still another way consists in looking at the types of justifications invoked by states that the court has considered acceptable. And here, the justifications that consist in justifying age limits through concerns of distributive justice between successive cohorts are crucial. We will return to this aspect in the next section.

Our second question is: what does our fourfold test tell us about the complete-life view on the distinctiveness of age and the three accounts ('complete-life neutrality', 'sequence efficiency', 'affirmative egalitarian') that we have associated with it in the previous section and in this one? First, the fact that our age changes and that we will successively belong to the included and the excluded categories is crucial to each of the three accounts. If this were not the case, a disadvantageous age criterion would necessarily lead to a disadvantageous situation over complete life. Second, the scope of the three accounts is broad if they are taken together. This is so especially as the numerous cases in which the 'complete-life neutrality' does not work can still be accounted for by the 'sequence efficiency' or the 'affirmative egalitarian' views. Third, within their scope, each of these three accounts is able to justify a more lenient approach to age-based differential treatment than the one that applies to, e.g., gender or 'race'.

30 Two specific bodies of evidence support this claim. First, the 'summer learning loss' shows that the skill gap becomes larger after the summer holidays than before between kids of different socio-economic background. Second, there also seems to exist evidence that longer school days benefit disproportionately to children from more disadvantaged background. See more generally Richard Rothstien, Class and Schools: Using Social, Economic, and Educational Reform to Close the Black-White Achievement Gap (New York: Teachers College Press, 2004). Note that the interesting question in this example is to disentangle the isogenic effects of compulsion from the specific role played by age. 
Finally, are these three 'complete life' accounts of the specialness of age independent from the 'reliable proxy' one? I have shown why the 'reliable proxy' account cannot justify extra leniency without an extra account. Any of the three 'complete-life related' accounts can function as this extra account, despite the fact that we have insisted on the limitations of the 'complete-life neutrality' one. My guess is that measures supported by the 'affirmative egalitarian' account will be the most defensible ones and that the 'reliable proxy' and the 'sequence efficiency' ones need at least the 'complete-life neutrality' view as a complement. Admittedly, 'sequence efficiency' can also work in tandem with 'reliable proxy' to account for the specialness of age. The inter-relations between these different accounts are thus a little bit complex.

\section{Age Criteria and Birth Cohorts}

Do the four accounts defended so far ('reliable proxy', 'complete-life neutrality', 'sequence efficiency', 'affirmative egalitarian') fully capture the specialness of age? I think that they define what is at the heart of this distinctiveness. However, in this section and in the next one, I will explore two further dimensions. The first one has to do with the scope of the previous accounts - and especially of the 'complete-life neutrality' and of the 'affirmative egalitarian' ones - and with the scope of the prohibition on age discrimination.

Let us consider a very important distinction - familiar to social scientists in general and to demographers in particular - between age groups and birth cohorts. An age group is a group of people sharing the same age at different periods in history. People who were 44 in 767 and those who are 44 in 2014 belong to the same age group. A birth cohort is a group of people born during the same period. Those aged 34 in 2004 and 44 in 2014 belong to the same birth cohort as they were all born in 1970. Demographers rely on the notions of 'period,' 'age group' and 'birth cohort' to try and disentangle three types of effects (period, age and cohort effects). For instance, if the values of those who are 34 in 2004 differ more strongly from the values of those who were 34 in 1904 than they do from the values of those who will be 64 in 2034, it may suggest that our values are more affected by cohort effects than by age effects. ${ }^{31}$ And if the heart condition of those who were 80 in 1880 is closer to the heart condition of those who were 80 in 1980 than it is from the heart condition of those who were 20 in 1920, age effects may be more significant than cohort effects here.

This distinction between age groups and birth cohorts is crucial. It allows us to understand three things. First, once we join together the complete-lives understanding of what justice requires with the concern for fairness between people from different birth cohorts, we come to understand why the latter should have priority over a concern for equality between age groups. Yet, this doesn't mean

31 See, e.g., Ottar Hellevik, 'Age Differences in Value Orientation: Life Cycle or Cohort Effects?,' International J. of Public Opinion Research 14 (2002): 286-302. 
that the three previous 'complete life' accounts and the 'birth cohort' account of the specialness of age discrimination are identical. We can perfectly rely on 'complete life' approaches to assess the acceptability of an age criterion in a world consisting of a single birth cohort.

Second, what drives age limits does not necessarily only involve age effects. Admittedly, for many age limits, especially those that target young people (e.g., child labour, compulsory education, sexual majority), age effects are central. However, it is plausible to ground, e.g., age-based compulsory retirement measures in a mix of age-related concerns (effect of age on the productivity of workers; effect of seniority pay on the ratio between spot productivity and spot wage) and of cohort-related concerns (compulsory retirement as a way of redistributing jobs between birth cohorts). Similarly, emphasizing the importance of mixing the worldviews of young and old academics - as in the Georgiev case, $\S 46$-, may imply a combination of cohort and age effects. As said, our values tend to be affected both by the specific historical periods we went through and by our age.

Third, and most importantly, independently of what motivates age-based policies, anti-age-discrimination law can actually aim at scrutinizing differential treatment between age groups as well as differential treatment between birth cohorts. The use of the word 'age' does not force us to limit ourselves to the 'age group' dimension at all, as a person's age is perfectly correlated with her date of birth. While we have seen that age limits do not always lead to differential treatment between birth cohorts, they often do. Conversely, all measures that define their personal scope through reference to the date of birth of individuals automatically lead to transitory age-based differential treatment. This age-cohort connection makes age discrimination special. And it potentially allows us to use anti-age discrimination law to combat discrimination between birth cohorts.

Do we find traces of such a concern for non-discrimination between birth cohorts in the ECJ's case law? Indirectly, yes. In several of its decisions, the Court regards the idea of 'shar[ing] out among the generations employment opportunities' (Petersen, C-341/08, § 65), 'sharing employment between the generations' (Rosenbladt, C-45/09, § 43), 'balance between the generations' as a legitimate aim (Georgiev, C-250/09, § 42; Fuchs \& Köhler, C-159/10, § 47) and 'free[ing] up posts for younger workers on the labour market' as a legitimate aim (Hörnfeldt, C-141/11, § 25). Admittedly, the ECJ does not go as far as claiming that anti-age discrimination law commands that discrimination between birth cohorts be banned. However, while this list of quotes is compatible with a reading both in terms of age groups and in terms of birth cohorts, a job allocation goal - deemed legitimate by the Court - is arguably most defensible under a cohortal interpretation, if we agree that equality between age groups is philosophically less defensible (if at all) than equality over complete lives. ${ }^{32}$ 
More interestingly, the Court itself seems to adopt a cohortal interpretation of such a goal in Commission v. Hungary (C-286/12). ${ }^{33}$ The act under consideration consisted in abruptly lowering the compulsory retirement age of judges and prosecutors from 70 to 62 . One of the goals invoked in support of this measure by the Hungarian government was the idea of a 'more balanced age structure facilitating access for young lawyers to the professions' ( $(76)$. There are two reasons supporting the view that the ECJ interprets this goal in cohortal terms, even if its language is not explicit. The first indication comes from the analysis by the Court of the ability of the measure to contribute to that goal in the short term. It says that 'it must be held that, as noted by Hungary, the lowering of the age-limit for compulsory retirement will result in the vacation of numerous posts which will be liable to be occupied by young lawyers, as well as in the acceleration of the rotation and renewal of the personnel within the professions concerned' (§ 76). The Court characterizes these effects as positive in the short term from the perspective of a balanced age structure $(\S 77)$. Now, if we interpret this through the prism of age groups, even if we were to assume that the eldest age group was overrepresented, it is hard to understand how - even in the short term - the complete exclusion of an age group (the 62-70, on top of those above 70) could possibly make an age structure more 'balanced.' This would make no more sense than saying: 'Excluding all Asian workers from our profession will make the ethnic mix more balanced.' There is no reason to take 'balancing' and 'rejuvenating' as necessarily equivalent. The only reading that can make sense here is a cohortal one, considering a lower compulsory retirement age and the consecutive increase in the rate of turnover as a way of distributing jobs between successive cohorts in a more balanced way.

There is a second indication of such a cohortal analysis by the ECJ in this case. While it considers its short-term effects positive, the Court ends up concluding that the measure is not appropriate to achieve the objective of a more balanced age structure in the medium and long term. What is interesting is the way in which it argues for it at $\S 78$ :

'While, in 2012, the turnover of personnel in the professions concerned will be subject to a very significant acceleration due to the fact that eight age groups will be replaced by one single age group, namely that of 2012, that turnover rate will be subject to an equally radical slowing-down in 2013 when only one age group will have to be replaced. In addition, that rate of turnover will slow down progressively as the age-limit for compulsory retirement is raised progressively from 62 to 65, pursuant to Article 18(1) of the Tny Law, leading, in fact, to a deterioration in the prospects for young lawyers of entering the professions of the judicial system' (my italics).

While the Court uses the phrase 'age group', note that it labels it with a date of entry rather than with an age ('namely that of 2012'). Moreover, let us distin- 
guish the rate of turnover from fluctuations in this rate of turnover. If one lowers the age limit (even if one only does so to 65 instead of 62 ), one mechanically increases the rate of turnover. People will tend to stay in the profession for a shorter period of time. If the number of jobs remains relatively constant, it is hard to see how this will not lead to a higher representation of the youngest age groups in the medium and long term too. There is thus no reason to draw a different conclusion from the one adopted by the Court on the short term. How then to explain the ECJ's negative assessment? The insistence on fluctuations in the rate of turnover (acceleration, deceleration and deceleration again) suggests a concern for the differential impact of these fluctuations on successive birth cohorts during the transition period, rather than on different age groups.

The exact implications of a concern for age in anti-discrimination law for the issue of discrimination between birth cohorts would require more extensive developments. What is clear is that opening the door to the extensive scrutiny of national legislations on grounds of a concern for non-discrimination between birth cohorts is potentially of very significant implications. Now, the "birth cohort' account of the specialness of age as a suspect ground tells us that when we treat age groups differently, we often treat birth cohorts differently. It also tells us that when we treat birth cohorts differently, we always treat age groups differently at a given point in time during transition. A typical example is when we define the scope of a rule through the conjunction of an age and a date (e.g., 'those having reached the age of $\mathrm{x}$ by date $\mathrm{y}$ are exempted from ...'). While the use of age criteria may lead to differential treatment between birth cohorts, one should not lose sight of the fact that for the 'affirmative egalitarian' account age criteria may also serve equality between birth cohorts. In such cases, combatting age-based differential treatment could worsen inequalities between birth cohorts.

The complex nature of the 'age-group/birth cohort/age criterion' relationship is clearly related to the fact that our age changes. Moreover, the 'birth cohort' account is not totally independent from the 'complete life' accounts. It simply gives a sense of the extension of their scope. While someone indifferent to inequalities between birth cohorts could still find it appropriate to adopt a complete-life view to compare people within the same cohort, people who are concerned about justice between birth cohorts will have a hard time drawing normative conclusions from inter-cohortal comparisons without adopting a complete-life view. Insofar as the scope of this 'birth cohort' account is concerned, it is potentially very broad. Whether it tends to justify more leniency on age-based differential treatment - in comparison with gender or 'race' for instance - is not straightforward. I don't think that this account adds further support to the support already provided by the previous accounts. Whenever age criteria will serve the goal of more equality between birth cohorts or will be neutral over complete lives, it will confirm the view that extra leniency is justified. However, as we have seen, age criteria, often do entail differential treatment over complete lives that do not necessarily have isogenic effects. 


\section{Chosen Age}

Let me complete this exploration by mentioning a final feature that renders age distinctive. We have insisted at the beginning on the fact that we don't choose the age we have, as we don't choose our 'race.' The fact that our age changes does not make it more chosen, even though it makes it possible, if certain conditions are met, that differential treatment on this ground would not lead to any differential treatment over complete lives. There is, however, an extra dimension to consider: we don't choose the age we have, but we are often able to choose the age at which we do certain things. While we don't control the change in our chronological age, we can choose to wait and do certain things at a later, and possibly more appropriate, moment. And we can also choose not to wait and get things done earlier. While we cannot choose the gender with which we do certain things, or the 'race' with which we do them, we can, up to a certain point, choose the age at which we do these things.

Prohibiting people from working before and after a certain age is premised on the idea that certain timings are more desirable than others. It is also premised on the idea that people will still have a chance to get access to, e.g., paid work when their age will be such that the prohibition on child labour does not apply anymore and before they reach the age of compulsory retirement. Another good example is insurance. For risks that decrease with age, one tends to encourage people to wait (e.g., driving before 25 or not). And for risks that increase with age (e.g., age-related health risks), an insurer will encourage people to begin subscribing at an early age. ${ }^{34}$ We can suspect that differentiated premiums on the basis of age will seem less acceptable if people don't have the choice of timing, for instance if they live in a society where urban planning is such that it is impossible to move without a car, or where young people experience a labour market such that they are financially unable to begin subscribing for a life insurance at an early age. Similarly, incentives for women - and couples more generally - to have children earlier will seem less acceptable in a society where the early years on the job market don't provide any financial security.

I suspect that this 'chosen age' feature plays some role in the intuitions we have about the acceptability of age criteria. Its precise articulation with the 'reliable proxy + complete life' accounts is not straightforward, however. Can we imagine cases where we would find age limits acceptable because of the 'chosen age' idea independently of the complete-life idea? It is hard to identify such cases if we adopt a responsibility-sensitive metrics that is interested in whether you had the opportunity to do things at a certain time, regardless of whether you did in the end or not. Conversely, can we imagine cases in which age limits would prevent us from doing things that we are only able to do at a given age, with the same impact over complete lives for all of us? Imagine that most people beyond 80 are unable to run a marathon. We could imagine a rule preventing those who didn't reach 80 
yet to run marathons. However, such an age limit would amount in fact to a plain prohibition on running marathons. The complete-life impact will be identical for most of us. Presenting this as an age-based measure would be strange. This suggests that in practice there is a full overlap between the 'chosen age' and the 'complete life' accounts. And it is probably safe to say that it plays an especially important role in the acceptability of the 'sequence efficiency' account. Finally, the chosen age idea can justify extra leniency towards age-based differential treatment.

\section{Conclusion}

Age is special. And the reasons why we rely on age criteria are multiple and intertwined. We have shown that all the accounts presented are connected to the fact that our age changes along our life. However, merely pointing at this fact is insufficient to establish its moral acceptability. We have indicated that the 'reliable proxy' account plays an important role in this story and that the ECJ's case law supports the use of age as a proxy up to a certain point. And yet, the 'reliable proxy' account is insufficient to ground for the moral specialness of age. The same holds not only for the 'temporary harmfulness' but even for the 'complete-life neutrality' account, notwithstanding the fact that the 'complete-life view' points at the philosophically most original feature behind age discrimination. The 'reliable proxy' and the 'complete-life neutrality' account both face two limits. Insofar as the former is concerned, the correlation with the target variables is only significant at the youngest and most advanced age and reliability does not automatically entail moral acceptability. Similarly, the 'complete-life neutrality' account is only factually valid in a more limited set of cases than we think and it is also morally insufficient as the 'gender rotation' argument indicates.

This being said, the 'complete life' feature is present as well in the two affirmative accounts that we regard as crucial, i.e., the 'sequence efficiency' and the 'affirmative egalitarian' ones. Their scope may be limited. However, within their scope, they offer robust defences of age-based differential treatment. One of the practical implications of the 'affirmative egalitarian' one is that we should not prematurely get rid of the age-based measures that in fact promote equality over complete lives between people including across different birth cohorts. Combatting age discrimination should not come at the price of increasing inequalities between birth cohorts even further. Compulsory retirement provides us with a good illustration of such a risk. It is likely to be an important issue in the coming years. Of course, its acceptability cannot be assessed without looking at the specifics, such as whether we could substitute cumulate-seniority-based to age-based compulsory retirement, whether such a substitution is likely to take place, or whether the measure is enforced in a jurisdiction where a decent pension system is in place for those who are expected to retire.

In the end, it turns out that a full understanding of the specialness of age-based differential treatment requires that we consider together the 'reliable proxy', the 
'complete-life neutrality', the 'sequence efficiency' and the 'affirmative egalitarian' accounts. Depending on the specific age criteria, all four accounts may apply or only some of them. This is the first key message of this paper. The second key message has to do with the age group/birth cohort distinction. All measures that have a differential impact on different cohorts also tend to have a differential impact on various age groups during the transition. We should fully explore the practical implications of anti-age discrimination law for differential treatment between birth cohorts. I suspect that they could be very significant. Interestingly enough, there is evidence from the ECJ's case law that this is a dimension that it is sensitive to and that is examines in the age cases. 